\title{
Harnessing Social and Collaborative Tools in Digital Disaster Response Work: Implications for Design and Practice
}

\begin{abstract}
This paper explores the implication of the use and appropriation of collaborative technologies in digital disaster response. Using a virtual ethnographic approach, we studied the work of Humanity Road through participant observation of seventeen response operations across thirteen countries for seventeen months. The results identify critical areas where collaborative technologies have been successfully deployed for organising disaster responses. Our analysis offers insights into the areas where these technologies have facilitated or hindered the capacity of cooperative work during response operations. We conclude by suggesting implications for design and practice.
\end{abstract}

\section{Keywords}

Crisis informatics; crowd work; digital disaster response; disaster management and governance; social and collaborative tools

\subsection{Introduction}

Understanding how people appropriate technologies in an organisation has, for a long time, remained a central concern for researchers in social and collaborative computing domains (Dourish, 2003; Mark and Semaan, 2008). This concern has more recently become especially relevant as organisations and groups have adopted the use of social and collaborative platforms such as Facebook, Twitter, GoogleDocs, and Skype into their work practices (Starbird and Palen, 2010, 2013; Abdulhamid, Perry and Kashefi, 2018). Recent use of these technologies during mass shootings in the US, the 2011 England riots, and in several disasters have triggered further academic interest regarding their use (Reuter and Mentler, 2018; Reuter, Hughes and Kaufhold, 2018). Some of these interests revolve around studying how organisations and groups adopt their use to initiate opportunistic shifts into their work structure and coordination mechanisms (Hughes and Palen, 2009; St. Denis, Hughes and Palen, 2012). To date, scholars in the field of social and collaborative computing are still exploring the entanglement between people, organisational culture, process as well as these technologies.

So far, a review of the existing literature on the appropriation of social and collaborative tools in disasters tends to fall into three main themes. These themes revolve around understanding the use of such tools by citizens, public and private organisations /agencies during emergencies. Others involve examining the work of spontaneous volunteers and that of digital volunteer communities. In particular, studies that examined the appropriation of technologies by citizens, public and private organisations and agencies mostly focused on understanding the appropriation of specific tools, or exploring the process and developing techniques, systems or heuristics (Palen, Hiltz and Liu, 2007; Starbird and Palen, 2011). On the other hand, the literature on the appropriation of collaborative platforms by spontaneous volunteers focused mostly on understanding their self-organisation, information sharing, social behaviours and information quality concern (Starbird and Palen, 2010; Tapia, LaLone and Kim, 2014; Peters and de Albuquerque, 2015). Lastly, studies on established digital volunteer communities, revolve around studying their work practice, evaluating existing platforms, and designing and developing tools and platforms to support their activities (Gupta et al., 2014; Ludwig et al., 2015).

Taking a more focused approach, our work specifically examined the implications of adapting and re-appropriating a range of technological tools and platforms to enact new patterns of action for work and social interaction in a workplace. Our motivation for focusing on this area is based on the fact that the literature is relatively thin with regards to the use of social and collaborative technologies in digital disaster response and how these tools work in practice (St. Denis, Hughes and Palen, 2012; Reuter et al., 2015). 
Furthermore, even the studies that examined the utilisation of such platforms tended to limit their work on the use of specific tools such as Flickr (Liu et al., 2008), Facebook (Vieweg et al., 2008) and Twitter (Heverin and Zach, 2010). Others that go beyond focusing on one specific tool have also limited their scope to a single case study or examine workplace practices of groups that do not fall within the established digital volunteer communities' ecosystem (Starbird and Palen, 2013; Cobb et al., 2014). For example, in a study that sought to understand the implications of deploying a team of trusted volunteers to work side by side with the emergency management team (St. Denis, Hughes and Palen, 2012), an attempt was made to outline the use of tools in organising their work. Although insightful, the work does not provide little insights into the workplace realities of appropriating social structures by the established digital disaster response groups.

Against this background, an opportunity exists to provide insights into the workplace realities about how the appropriation of collaborative tools can contribute to the success or failure of digital disaster response work. We do so by answering the following research question: How are digital volunteer communities enacting new patterns of action and social interaction using social and collaborative tools in a workplace while responding to disasters, and how does it work in practice?

We conducted our work through an in-depth remote study of an Internet-based digital volunteer, not-for-profit organisation for seventeen months. This work expands our knowledge of the salient but under-reported practical field challenges in the use of various collaborative technologies.

In the following sections, we reviewed the literature and provided background and case study context. This is followed by a description of our research approach where we discuss data collection procedures, identification and choice of cases as well as our approach to data analysis. Next, we present the results, discuss the implications and conclude our work.

\subsection{Social Listening and \\ Collaborative Technologies in Digital Disaster Response}

In what follows, is our review of the past studies related to the established digital volunteer communities as well as on the use and appropriation of collaborative technologies.

\subsection{Established Digital Volunteer Communities}

This study is not about a spontaneous group of volunteers that emerged and converged as bystanders during a disaster and disappear shortly afterwards (Kreps and Bosworth, 2007). Its focus is on social media and data aggregation communities, which is one of the four established digital communities based on Gorp (2014) delineation of established groups. It is worthy of mentioning that studies on digital disaster response are interdisciplinary. Hence, there is a lack of unanimity from the literature on the nomenclature upon which these groups are named after (Abdulhamid, Perry and Kashefi, 2018). Against this background, this study takes a cue from a previous study (ibid.) by sticking to the use of digital volunteer communities (DVC) for clarity purpose.

\subsection{Appropriation of collaborative technologies}

From our review, literature about how users' appropriate technologies are varied and diverse. Earlier studies approached this phenomenon by examining the appropriation of specific tools (Bowers, Button and Sharrock, 1995; Orlikowski, 1995), or investigating challenges associated with using a range of tools, (Harrison and Dourish, 1996; Mark and Semaan, 2008; Mark, Al-Ani and Semaan, 2009). Overall, these studies have taught us that regardless of the intent of system developers, use and appropriation of tools can give birth to some unintended consequences. For example, there is a mismatch between what the system expects from users and what users understand how the system is supposed to be appropriated (Kaptelinin, 1996). Others include how users recreate, adapt, manipulate, circumvent, 
abandon, or develop a new pattern of action and social interaction while using such mediating tools and platforms at an individual and group level (Mark, Al-Ani and Semaan, 2009).

On the other hand, review of the existing literature on the use of collaborative technologies in humanitarian emergencies tended to revolve around the evaluation of the existing tools as well as their use among emergent and established groups. Earlier studies related to this field assessed existing platforms and tools and thereby developed alternative ones. Some of these studies developed platforms that can support the activities of volunteers in tracking, organising, visualising and reporting actionable information (Cobb et al., 2014; Gupta et al., 2014). Reuter et al. (2015) work examined the use of existing social media tools, platforms and approaches among volunteer communities to understand the challenges associated with their use in crisis management. However, since the focus of their work was on developing a scalable application that can overcome the limitations of the existing tools, the study does not provide insights on how such tools are appropriated in practice during disaster response (Ibid.).

On the other hand, the non-technical oriented field related to social and collaborative computing tended to focus on how emergent volunteers make use of a range of tools. For example, the literature is replete with the use of platforms such as Google Docs, Skype, Emails, Twitter, and Facebook to converge and self-organise while responding to events. (Palen, Hiltz and Liu, 2007; Starbird, 2011). Likewise, past studies explore the information-seeking practices of communities during disasters using a range of ICT platforms. For example, during the 2007 Southern California wildfires a study revealed how users that were geographically dispersed leveraged ICT to build community resources and find community-specific information (Shklovski, Palen and Sutton, 2008).

As for studies that examine the appropriation of tools by the established groups, their focus tended to revolve around highlighting the type of tools without emphasizing on how their use enabled or constrained disaster response (Starbird and Palen, 2013; Cobb et al., 2014).

\subsection{Background and Case Study Context}

Humanity Road (HR) is a non-profit volunteer-based digital disaster response charity founded in 2010 with its headquarters based in Virginia, USA. The primary responsibility of this organisation is to help connects people and aid agencies with information as a source of aid when disaster strikes. They do so by leveraging the Internet and mobile communication technologies to collect and verify social media disaster-related messages and route out the refined verified actionable information to the government and aid agencies and vice versa. These volunteers' passion was born out of the understanding that during emergencies "people need information as much as water, food, medicine or shelter" (International Federation of Red Cross And Red Crescent Societies (IFRC), 2015, p. 12).

HR members include a range of specialists and professionals such as retired military officers, emergency managers, academics, students and health professionals, among others. Analysis of the internal documents shows that HR has members from across the globe, including Canada, Ecuador, Germany, Ghana, India, Nigeria, the UK, and the USA.

HR makes use of Skype as its core platform to coordinate the activities involved in accessing, organising, triaging, verifying, sharing and curating actionable disaster information.

\subsection{Research Approach}

This research draws from the work of Starbird and Palen (2013) to study how established digital volunteer communities (DVCs) make use of collaborative technologies while responding to disasters and emergencies. Starbird and Palen (2013) employed virtual ethnography by participating and observing the work of these (digital) volunteers through the Skype windows of their case study 
organisation. Likewise, in this study, the first author took the role of participant-as-observer, where he combined some level of participation with the observation (Gold, 1958) from 15th February 2016 to 22nd May 2017. The first author, who was a volunteer and a researcher observed in detail how HR volunteers were appropriating a diverse range of technological platforms and tools. In particular, his observations focus on how these volunteers use, modify, circumvent, abandon and exploit such tools and platforms in their activities while responding to humanitarian emergencies.

\subsection{Data Collection Procedures}

To have a broader insight on how these volunteers' appropriate collaborative technologies, we collected data through field notes arising from the participant observation, internal digital records and followed up with interviews. Before the commencement of the field study, HR asked the first author to insert the word "Researcher" in front of his Skype name so that volunteers will be aware of his presence in all the Skype chat rooms. Thus, to understand volunteers' actions and how they respond to disasters, the first author was given access to 6 different Skype Windows to enable him to participate in meetings, internal drill exercises as well as real disaster response operations. During such period, he attended meetings, participated in internal drill exercises and real-life response operations. During the observation period, our first author attended three standing committee meetings, ten special projects meetings, two extraordinary meetings, five traditional pieces of training and thirteen internal drill exercises. Furthermore, he participated in twelve disaster response operations. He opted to observe five with the view to have insight on the difference between immersion in the activities and an outsider seeing how volunteers respond to disasters using collaborative technologies.

In addition to the field note from the participant observation, we used Skype chat $\operatorname{logs}$ of all the response operations our first author participated in or observed. HR granted permission to use the Skype chat logs with the condition that all personally identifiable information be anonymised unless a volunteer expressly agreed to be made public. Previous studies in Human-Computer Interaction (HCI) have also used chat logs from different services such as Skype, Google hangout or other customised applications (Smith, Farnham and Drucker, 2000; Starbird and Palen, 2013).

Besides participating and observing the activities of volunteers, we conducted interviews through Skype to follow up issues requiring further clarification. All in all, fifteen participants were contacted, but nine agreed to take part. However, only seven showed up. As such, we conducted seven semi-structured interviews. Each interview lasted for averagely 50 minutes apart from two interviews. The interview questions covered personal experiences and reflections, organisational culture, use and appropriation of tools and lessons learnt.

\subsection{Identification and choice of cases}

To enable us to have a broader understanding of the use of collaborative tools used by digital volunteers, we tried to cover a full range of disasters (events). As a result, we draw upon Fritz's (1961, as cited in Kreps, 1984) core properties of disasters for selecting the unit of analysis. These units of analysis include events, social units and response type. Events are defined as disaster types which could be small or large. Social units could be individuals, family, region, country or continents affected by the disaster. Response type refers to the degree of emergency response mobilisation alongside the time taken to give relief to the affected communities (ibid.). Thus, we chose events such as dam spillage, earthquakes, explosions, flooding/landslide, severe weather, wildfires alongside a particular project on Burundi Hospital emergency response operations.

Our selection of these events covers thirteen countries (social units) representing six continents - Africa, Asia, Europe, North America, South America, and Oceania. These countries are Belgium (Brussel), Burundi, Canada (Fort McMurray), Chile, Ecuador, Fiji, Italy, Japan (Kumamoto), Manchester 
(UK), Peru, Sri Lanka, Turkey (Istanbul), USA (Oroville). Table 1 provides a more detailed classification of the type of events our work covered alongside the countries as well as their associated continents.

Table 1. Summary of the disasters covered

\begin{tabular}{|c|c|c|}
\hline \multirow{2}{*}{$\begin{array}{l}\text { EVENTS } \\
\text { (TYPE) }\end{array}$} & \multicolumn{2}{|l|}{ SOCIAL UNITS } \\
\hline & COUNTRY & CONTINENT \\
\hline Dam Spillage & USA (Oroville) & North America \\
\hline \multirow{3}{*}{ Earthquake } & $\begin{array}{l}\text { Japan } \\
\text { (Kumamoto) }\end{array}$ & Asia \\
\hline & Ecuador & South America \\
\hline & Italy & Europe \\
\hline \multirow{3}{*}{$\begin{array}{l}\text { Bomb } \\
\text { Explosion }\end{array}$} & $\begin{array}{l}\text { Belgium } \\
\text { (Brussel) }\end{array}$ & Europe \\
\hline & Turkey (Istanbul) & Asia \\
\hline & Manchester (UK) & Europe \\
\hline \multirow{2}{*}{ Flood/Landslide } & Sri Lanka & Asia \\
\hline & Peru & South America \\
\hline Special project & Burundi & Africa \\
\hline Severe weather & $\begin{array}{l}\text { Fiji Tropical } \\
\text { Cyclone }\end{array}$ & Oceania \\
\hline \multirow{2}{*}{ Wildfire } & $\begin{array}{ll}\text { Canada } & \text { (Fort } \\
\text { McMurray) } & \end{array}$ & North America \\
\hline & Chile & South America \\
\hline
\end{tabular}

Our justification for choosing these countries across six continents evolved out of our curiosity to uncover whether the type of response operations provided by HR differs from one continent to another. Additionally, we wanted to figure out whether there exists any variation in the use of collaborative tools considering the differences in socio-historical, cultural, and political contexts across countries.

\subsection{Data Analysis}

As previously mentioned, the data used in this study include Skype chat logs, notes from field observations, transcribed interviews and internal documents. As a result, the analysis of the data was carried out in two stages. The first phase involves the analysis of Skype chat logs and observation field notes following the set of principles of thematic analysis as a method of qualitative data analysis for finding, appraising and reporting patterns (themes) within the collected data (Braun et al., 2014). The process began with careful reading and re-reading of Skype chat logs (799 pages of Microsoft Word documents) to gain a holistic overview of the main themes and to get the flavour of the use collaborative technologies. These readings enabled us to start finding related concepts/ideas and recognising recurring patterns. This formed the first phase of data analysis in which we identified recurring sub-themes such as GroupTweet, Skype, Google Docs, and Translation tools, among others. Based on the initial findings, we combined Activity Oriented Design Method alongside Martins \& Daltrini framework as an interpretive lens to help us understand the data as described in section 2. In our finding's sections, we highlighted the primary constructs of the activity theory (subject, object, tools, communities, division of labour, and rules) alongside actions, operations and activities using bold italic.

\subsection{Findings}

The findings of the study provide insights into the appropriation of technological tools and platforms by volunteers with regards to their benefits and challenges in digital disaster response operations. The focus is mainly on the volunteers' interaction with Google Docs, GroupTweet, Twitter, Skype and translation search engines. Three considerations informed the rationale for choosing these tools in highlighting the implication for their deployments. First, HR internalised their usage across all their activities. Second, HR dedicated time to develop best practice and drill exercises on their use as well as trained its volunteers in using it. Third, most of the discussions on the capabilities and constraints of using these tools revolved around Google 
Docs, GroupTweet, Twitter, Skype and translation search engines.

\subsection{Working with Google Docs}

Google Docs (tool) is a web-based word processing platform that offers users the capability to collaborate and co-author documents in both synchronous and asynchronous ways. HR adopted Google Docs as part of its core platform for conducting its activities such as authoring of sitreps (situation reports) that required the collaborative effort of its volunteers (subjects) holding different roles (division of labour) in the organisation. HR is responsible for creating and managing Google Docs. As a result, access to such document is granted (rules) by the Vice President (VP) Operations.

Producing a situation report (sitrep) involves the distribution of work by social media incidence commander (SMIC) who will set the target and scope of the work and encourage volunteers to point out areas they will work on. For example, some volunteers will focus on adding names (actions), addresses and contact details (actions) including social media handles of relevant stakeholders on the report. Others will focus on adding (actions) verifiable information from the disaster-affected communities or response updates from the emergency management organisation and aid agencies. Others will work on transferring (actions) verified content shared by volunteers from various Skype windows, among other things.

Although Google Docs provides flexibility for HR volunteers to seamlessly coauthor sitreps, analysis of the empirical data revealed that its appropriation sometimes comes with some pocket of challenges. For example, during significant disaster responses such as the Japan and Ecuador earthquakes, the Louisiana flood as well as Fort McMurray wildfire, several complaints emerged namely; 'Google docs is lagging', 'it is unresponsive', 'it just kept freezing', 'I could not copy things'. Other complaints include some volunteers' inability to 'highlight' a text 'in order to add a link or cut or paste' actionable information on the sitrep.
Analysis of the chat logs and follow up interviews revealed that volunteers overcome some of these challenges by encouraging users experiencing such problems to 'sign out' and 'sign in' or to 'reboot the system' the user is working with. In the event the problem persists, the user is advised to 'clear the cookies' from the owner's browser and then try to sign in again. According to the HR Vice President (Cat Graham), 'cookies can really impact how information is displayed on your screen and sometimes cookies can really interfere with it as well, and if you don't refresh or remove your cookie, it can give you a different experience'. However, if the problem is perceived to be a group problem, Cat Graham states, 'I might remove them from the docs and re-add them and ask them to close the docs and open it again in a new window'. In summary, the practical approach of overcoming the challenges include signing out, signing in, clearing browser cookies, rebooting the system, opening an incognito window as well as the 'remove and re-add' approach.

\subsection{Working with GroupTweet}

GroupTweet (tool) is a third-party application for Twitter that allows multiple contributors (subject) to share a tweet to the organisational account from their personal (Twitter) accounts. This is made possible when volunteers are added as contributors to the corporate account. Like Google Docs, HR VP Operations also handles the administration and management of GroupTweet. As such, access is granted (rules) to volunteers who attended training on GroupTweet (tool).

HR uses GroupTweet because it provides affordances for reducing workload and improving efficiency since volunteers can distribute tasks (division of labour). HR VP emphasised during an interview that 'GroupTweet, is the only tool right now that we can give to our volunteers since many hands can be doing a GroupTweet at the same time'.

Despite the affordances offered by GroupTweet, analysis of the empirical data reveals some challenges associated with its 
deployment. Our findings show instances across a range of events in which volunteers decried that GroupTweet 'isn't working', 'does weird things sometimes' or 'sometimes my tweets don't even show up at all'. At some point in time during the M6.3 Earthquake experienced in the Aegean Sea near Greece and Turkey, the SMIC had to stop using it and exclaimed that 'Grouptweet isn't picking up my tweet' and later went to on to say 'logging in to tweet from HR and I'm going to cancel grouptweet it fails too often - we need a better solution'(PH01). I essence, the SMIC had to abandon the use of GroupTweet and logged into an HR account to tweet. It is thus fair to assume that the only quick fix to the problem was to abandon the use of GroupTweet and $\log$ into HR Twitter account and share the information. HR VP Operation confirmed this situation during an interview in which she mentioned, 'Our staff will usually go on in such situations and sign for the HR twitter account'.

\subsection{Working with Skype}

For HR, Skype (tool) is its virtual headquarters and a core operational platform. It uses Skype to organise its entire response activities such as monitoring, coordination, communication, and training. Administratively, HR holds the access right for granting permission and adding volunteers to join its Skype windows. However, it gives such access rights after a volunteer has signed its code of conduct pledge and attended a mandatory onboard training (rules).

Despite the advantages Skype offers, our field experience and analysis of the empirical data revealed four different types of challenges associated with using Skype. First, service outages in which case volunteers are unable to send or receive messages. Second, delays in sending and receiving messages. Third, calls drop unexpectedly or unable to join group calls during briefing sessions. Last, is the challenge associated with information overload, which is a significant area of concern among HCI and CSCW scholars (Abdul-Rahman and Hailes, 2000; Hiltz and Plotnick, 2013). This type of challenge mostly affects volunteers joining the ongoing event in the Skype window coupled with the situation where they skim through a backlog of Skype chatter to be abreast with the response context. Similarly, the culture of creating event-specific windows during significant events, though helpful in some regards, adds to this challenge.

Our findings show that issues related to outage and delays in receiving and sending messages do not have precise workaround strategy. Since the problems are usually technical, volunteers must wait for the Skype services to be restored. HR President acknowledged that it hampers their ability to work with volunteers although 'HR uses the conference bridge to talk with one another (paid staff) to see who is doing monitoring and who is sharing on the social media'. Dropped calls, and inability to join group calls challenges are mostly overcome by asking volunteers to restart their systems or by using the 'remove' and 're-add' approach in which the admin will remove the user from the group call.

To overcome the challenge of information overload, HR developed a culture of creating a summary of the ongoing response in an 'Event Status and Information Sheet'. The 'Event Status and Information Sheet' is a hyper doc which contains summaries of the past and ongoing response operations. As such, the link is placed on top of the Urgent Event window (Skype). By doing so, volunteers can quickly locate the link and learn who is doing what, where and when.

\subsection{Working with Twitter}

Twitter is also a core tool and platform that HR uses in its day-to-day operations (tool). Analysis of the HR Twitter timeline suggests most of its tweets or retweets revolved around sharing situation reports and announcing public safety information and encouraging responsible sharing (action). Others include amplifying pertinent information from local, regional and national officials as well as volunteers, partners, and aid agencies (action). On the other hand, volunteers (subjects) leverage Twitter for data mining (action) urgent needs (such as medicines, 
evacuation, shelter, among others) and information that helps disaster-affected communities to sustain, survive and reunite.

Despite these benefits, analysis of the empirical data reveals design-related challenges that continue to hamper the effective use of Twitter by HR volunteers. For example, when in June 2017, Twitter refined the design of 'reply', 'retweet' and the 'like' icon, the update became a source of concern among some HR volunteers with disability, accessibility and some specific functional needs. The new design came with a light grey colour such that when a user hits the retweet icon, it changes to light green which makes it difficult for people with impairment and disabilities to easily navigate the new topography without putting extra effort. HRs Lea Knowles expressed her concern by saying that 'it is very hard for me to tell if I got everything retweeted'. Likewise, Kayla Baxter reinforced Lea Knowles concern by saying '... it is harder to see' and stated further that 'I've seen other people complaining too'. Another challenge relates to the inability of the Twitter design team to include a search bar or sorting functionality in the 'Twitter List'. A Twitter list is a functionality that allows for the curation of Twitter accounts into groups that could enable the curator to monitor tweets from the curated accounts. As such, volunteers will have to put extra effort and spend more time in their attempt to find accounts within the list. This hampers the ability of volunteers to make practical use of a tool whose central preoccupation is to make the work of people much more straightforward.

To overcome this challenge, volunteers worked around the issue of icon redesign by using the Safari reader view to enhance the colour contrast. As innovative as this approach was, it raises usability, accessibility and inclusivity concern for people that do not own iOS devices. As at the time of submitting this paper, the search bar and sorting option issue is still a problem.

\subsection{Working with translation tools}

In the context of HR's work, translation tools and platforms are technologies such as Google
Translate, Bing translator, Twitter, Facebook and Skype (tools) that enable volunteers to translate (action) and make sense of disaster messages. Translation tools are publicly accessible and so users do not need permission from any HR staff. Nonetheless, HR has dedicated sessions for training and improving volunteers' skills on how to use translation tools while responding to disasters.

Volunteers make use of translation tools to find urgent needs of disaster victims and also make sense of crisis information. As helpful as these tools are, a more in-depth look into how they render their translation revealed that they cannot be relied upon entirely without the supervision of a human translator. Most times, the translated texts are of low quality and hence challenging to convey the needed and relevant information required for decision making. We observed lamentations such as 'the machine translation for this is a bit weird' or 'Google translate is giving me weird translations' among others. From our finding, this 'weird' translation includes duplications of translated words, wrong placement of words in their proper places within a sentence, as well as the elimination of essential nouns. Others were the distortion of styles and inability for the machine learning algorithms to translate compound nouns written in other languages to English correctly. For example, during a response operation, a volunteer used Facebook generated translation to translate the following Italian phrase into English: 'Caserma Verdirosi' and 'dell 'aeroporto Ciuffelli'. The translator renderedthe following: 'barrack barrack' and 'airport airport' respectively instead of 'Verdirosi Barracks' and 'Ciuffelli airport'. It is worthy of mentioning that some translations tools are smarter than others as we have observed in our analysis while comparing Google translate with Facebook and Bing at that time. Not only that, our analysis also shows that there was no consistency when we subjected some of these tools to translate the same text over some time.

The main concern is the lack of precision from the machine-generated translation that limits volunteers' capability to share information as a form of aid in time. As 
a result, HR mostly resorted to training people from disaster-affected areas or volunteers from Translators Without Border (TWB), among others. However, for these on-boarded volunteers to join Skype operation window, they must undergo training to understand the HR code of conduct and response protocol. From our perspective, this hampers HR capability to provide information as quickly as possible knowing in responding to disasters, time, speed and accuracy are of the essence.

\subsection{Discussions and Implications}

As stated in our introduction, this study aims to provide rich insights into the work practices of the established digital volunteer communities. As such, we narrowed our focus to social media and data aggregation communities by studying their appropriation of collaborative technologies.

Our findings show that the use and appropriation of these tools and platforms provide both benefits and challenges. For example, these technologies enabled volunteers to monitor events, coordinate activities and communicate with fellow volunteers, aid agencies, emergency management organisations, disaster-affected communities and global online public. Also, volunteers took advantage of these tools to collaborate with partners, co-author reports, share situational awareness information as well as allowing volunteers to manage and administer organisational resources.

On the other hand, the appropriation of these tools also come with challenges that hampered volunteers' capability to provide information as a form of aid. From our perspective, these challenges were usercentred, process-centred, developer-centred or a symptomatic problem.

A user-centred challenge refers to the type of problems that an individual volunteer experienced from their end because of cookie interference or low internet bandwidth. As we have shown in our findings section, this type of challenge hampers the volunteers' ability to take part in a briefing call that in turn, will affect the overall group function. The processcentred difficulty arises because of the methods or official procedures put forward by the organisation (HR) in managing the activities of volunteers and response operations. For example, the policy of creating an event-specific window when responding to every significant catastrophe though helpful, contributed to the information overload. The growing number of HR Skype windows makes it difficult for individual volunteers to search and locate information quickly. It is often confusing to determine which window to search since a general search could reveal several inactive windows with potential answers. Similarly, the creation of event-specific windows made our work as researchers challenging. This has a long-term implication for future researchers who may want to undertake longitudinal research on the activities of digital volunteers utilising Skype as their core platforms. The Developercentred challenge includes both design and technical related issues. For example, the design-related problem revolves around the enhancement of the product such as that of Twitter.

In contrast, the technical problem includes issues such as server outages as experienced several times on Skype and the non-appearance of a tweet sent via GroupTweet. The inability of the GroupTweet to share the tweet during response implies a necessary implication towards the smooth running of the HR work. It could mean that several volunteers would not be able to share valuable information, thereby making the response work ineffective. The inability to display tweets has dire consequences since such information could sustain and unite afflicted communities

Symptomatic challenges are scalability and performance-related problems that occur because of the pressure put on the system, as seen in the use of Google Docs during response operations. Based on our understanding, such issues as 'lagging', and 'unresponsiveness' experienced by some of these volunteers cannot be dismissed as something inconsequential within the realm of humanitarian emergencies. The implication is that it affects the speed of the HR response. For example, when some volunteers became incapable of participating in an ongoing response, it affected the overall response goal 
where HR would be unable to publish the Sitrep and share it with emergency management organisations and partners working on the frontline. The impact is even more profound when the planning and decision-making process of partner organisations are dependent on the reports of HR. For aid agencies and emergency management organisations, speed, timeliness and appropriateness of information are vital. As such, if these tenets cannot be guaranteed, it affects their capability to provide aid.

From our perspective, developer centred, and symptomatic challenges are problems that HR or its volunteers have no direct control or significant influence in providing an immediate solution to. The only solution in sight is by abandoning the use of the tool as seen in the GroupTweet when the SMIC said, 'I am logging in to tweet from $H R$, and I'm going to cancel group tweets, it fails too often - we need a better solution'. However, what we found surprising is the inability of the organisation to provide alternative platforms for mitigating such occurrences. User-centred challenges appear to be more comfortable to handle through 'add and remove', 'log in and log out', 'deleting cookies' and the 'refresh' browser approach.

We argued that our rationale for studying a different type of disasters across countries was to allow us to understand whether the utilisation of tools and platforms differ across disasters or nations. Our finding does not show any significant differences. HR and its volunteers use the same type of tools regardless of the kind of disaster or geographical location. Nonetheless, such activity of monitoring several countries has exposed us to understand two exciting insights that are mostly overlooked by previous studies. For example, our research found that language is an essential factor that affects the smooth running of response operation. In other words, if volunteers are responding to disasters in a non-English speaking country, the amount of time it takes to verify information doubles. Apart from the language factor, our study also revealed the differences in digital disaster response readiness across developed and developing nations as will be explained in the following paragraphs.
Our participation and observation in various response operations and during internal drill exercise showed that coordinating disaster response outside English-speaking countries presented a challenge to the HR's operations. The reason was that most of the crisis information gathered from these countries were mostly in languages other than English.

For example, our participation in disaster response across Japan, Ecuador, Fiji and Peru revealed the kind of problems associated with machine-generated translation. The following excerpt from Skype illustrates a sort of challenge volunteers face while responding to disasters in a non-English speaking country like Japan during the Kumamoto earthquakes.

"[15/04/2016, 18:43:41] HR Javon Malone: Its big, and shallow. Not good. This is Japan so its going to be hard to work but I am sure this is going to be a major event".

The above chatter, as expressed by the social media incident commander, indicates the possibility of facing challenges while responding to the disaster in Japan. From the excerpt, volunteers read that statement as a kind of response that involved finding information in a language that most of the volunteers were not familiar with or understand. As such, it required the dual effort of using machine-generated translation tools which meant spending more time while trying to make sense of what is going on. To further confirm the perceived language difficulty, two days later, after a sudden earthquake in Ecuador, the same social media incident commander wrote in Skype window:

"[17/04/2016, 02:59:47] HR Javon Malone: Spanish is just as hard as Japanese...."

The above excerpt further reinforces the interpretation of the perceived difficulty volunteers experience while working in nonEnglish speaking countries.

This is crucial since responding to disasters in non-English speaking countries 
can be problematic and subsequently slow down volunteer effort. The translation tools that volunteers appropriate to make sense of the information were far from perfect. As such, HR devised additional effort to onboard and train native speakers or TWB volunteers that will work on the machine-translated information. This process of on-boarding and training native volunteers takes time and thereby slows the response efforts. Surprisingly, this dimension has received little attention in the existing literature.

On the other hand, the differences in information readiness from developed and developing nations became apparent to us as we observed the shortage of official information from government websites and emergency organisations in Burundi and Sri Lanka. We found that volunteers struggled to find information such as websites and social media accounts for ambulances, police, fire service and other rescue agencies. In Burundi, volunteers found it very difficult to locate addresses and information associated with health centres, schools, and police stations. Burundi and Sri Lanka are both developing countries as such this offers another perspective for future studies.

Against this background, the research community should take a cue from this study to understand the challenges associated with digital disaster response work. This is because some of the tools used by volunteers were designed to address the needs and preferences of general users. Thus, they lack specific features to address the needs of digital volunteers. As argued by Dourish (2003), past studies related to customisation in a collaborative system focused on approaches where features of the system's configuration can be made to suit the different settings in which the system might be used or the preferences of different potential users. This study demonstrates that some of these tools and the platform's lacked system configuration features that could allow for adjustment in different settings by a different set of users.

Based on the preceding, system designers need to start thinking of developing a system that suits the collaborative and cooperative work of digital volunteer communities. In particular, the proposed system should aim at assembling various components of system features that volunteers appropriate in coordinating their activities. For instance, combine Skype features (coordination), Google Docs (collaborative authoring), monitoring and verification tools and platforms that are used for data mining.

Besides, this proposed system could have a mechanism for organising information in a well-structured form. For example, the information management structure could be developed in such a way that it will allow for managing, classifying, archiving, downloading and searching for information in a systematic and structured way. Moreover, the proposed system could have features that can make interaction fluid and offer volunteers the ability to navigate seamlessly between various interfaces. Such features can include tags, pops up chatbots, disasterspecific emoji, and links to folders, resource list and major search engines, as well as live feeds. The tag features would help volunteers to locate frequently used methods, procedures or vital information. Pop up chatbots could provide recommendations and answers to frequently typed words and questions. Also, the proposed system could have an API that integrates the Office for the Coordination of Humanitarian Affairs (OCHA) 'humanitarian icons' which could complement existing emoji. The links to various resources such as folders, resource list, data mining, and search engines can help facilitate the work of volunteers. By developing such a system, designers can overcome some of the bottlenecks related to information overload and communication.

Concerning the discovery of differences in digital disaster readiness across nations, researchers can begin to think of how to establish a benchmark by studying disasterready nations and digital disaster response organisations. Doing so will allow for the development of a framework which can be adopt countries to be disaster ready.

\subsection{Conclusion}

Our study provides insight into the work practice of established digital volunteer communities. We do so by providing an indepth account on the use and appropriation of 
collaborative technologies with regards to how they enable and hamper the activities of volunteers. We specifically sketch out the use of Google Docs, GroupTweet, Skype, Twitter and translation tools by volunteers to provide information as a form of aid. The insights derived from studying disasters across nations of different infrastructural density could potentially signal the development of an evaluation framework for the standardisation of digital disaster readiness of such countries. This approach, therefore, offers a unique contribution to the methodological advancement of disaster research and crisis informatics. The findings from this research have important implications. It surfaces the salient but under-reported practical field challenges associated with the use of various collaborative technologies. By providing such insights, system designers and technology developers can utilise this information to improve collaborative work. Insights derived from the findings can also assist volunteers, aid agencies and emergency responders to adapt and improve the way they use social and collaborative tools in their daily routine. 


\section{References}

Abdulhamid, N. G., Perry, M. and Kashefi, A. (2018) 'Process Workflow in Crowdsourced Digital Disaster Responses', in Staab, S., Koltsova, O., and Ignatov, D. I. (eds) Social Informatics. Cham: Springer International Publishing, pp. 3-22. doi: https://doi.org/10.1007/978-3-030-01129-1_1.

Bowers, J., Button, G. and Sharrock, W. (1995) 'Workflow From Within and Without: Technology and Cooperative Work on the Print Industry Shopfloor', in Proceedings of the Fourth European Conference on Computer-Supported Cooperative Work ECSCW '95. Dordrecht: Springer Netherlands, pp. 51-66. doi: 10.1007/978-94-011-0349-7_4.

Braun, V. et al. (2014) Qualitative research in clinical and health psychology. London, UK: Macmillan International Higher Education.

Cobb, C. et al. (2014) 'Designing for the Deluge: Understanding \& Supporting the Distributed, Collaborative Work of Crisis Volunteers', Proceedings of the Conference on Computer Supported Cooperative Work (CSCW), pp. 888-899. doi: $10.1145 / 2531602.2531712$.

St. Denis, L. A., Hughes, A. L. and Palen, L. (2012) 'Trial by Fire: The Deployment of Trusted Digital Volunteers in the 2011 Shadow Lake Fire', 9th International ISCRAM Conference, (April), pp. 1-10.

Dourish, P. (2003) 'The appropriation of interactive technologies: Some lessons from placeless documents', Computer Supported Cooperative Work, 12, pp. 465-490.

Gold, R. L. (1958) 'Roles in sociological field observations', Social forces. JSTOR, 36(3), pp. 217-223. doi: $10.2307 / 2573808$.

Grudin, J. and Palen, L. (1995) 'Why groupware succeeds: Discretion or mandate?', in Proceedings of the Fourth European Conference on Computer-Supported Cooperative Work ECSCW'95, pp. 263-278.

Gupta, A. et al. (2014) 'TweetCred: Real-time credibility assessment of content on Twitter', Lecture Notes in Computer Science (including subseries Lecture Notes in Artificial Intelligence and Lecture Notes in Bioinformatics), 8851. doi: 10.1007/978-3-319-13734-6 16.

Harrison, S. and Dourish, P. (1996) 'Re-Place-ing Space: The Roles of Space and Place in Collaborative Environments', in Proc. ACM Conf. Computer-Supported Cooperative Work CSCW.

Heverin, T. and Zach, L. (2010) 'Microblogging for Crisis Communication : Examination of Twitter Use in Response to a 2009 Violent Crisis in the Seattle-Tacoma, Washington Area', Proceedings of the 7th International ISCRAM Conference. ISCRAM, 2009(November), p. 5.

Hughes, A. L. (2012) 'Supporting the Social Media Needs of Emergency Public Information Officers with Human-Centered Design and Development', ProQuest Dissertations and Theses, p. 265. Available at:

http://search.proquest.com/docview/1283376350?accountid=14643\%5Cnhttp://mlbsfx.sibi.usp.br:3410/sfxlc141?url_ver=Z3 9.88-

2004\&rft_val_fmt=info:ofi/fmt:kev:mtx:dissertation\&genre=dissertations+\%26+theses\&sid=ProQ:ProQuest+Dissertations + \%26+Theses+Global\&ati (Accessed: 2 September 2017).

Hughes, A. L. and Palen, L. (2009) 'Twitter adoption and use in mass convergence and emergency events', International Journal of Emergency Management. Inderscience Publishers, 6(3-4), pp. 248-260.

Imran, M. et al. (2013) 'Extracting Information Nuggets from Disaster- Related Messages in Social Media'. Available at: http://www.iscram.org/legacy/ISCRAM2013/files/129.pdf (Accessed: 17 June 2017).

International Federation of Red Cross And Red Crescent Societies (IFRC) (2015) World Disasters Report 2015: Focus on local actors, the key to humanitarian effectiveness. Switzerland. Available at: http://ifrc-media.org/interactive/wpcontent/uploads/2015/09/1293600-World-Disasters-Report-2015_en.pdf (Accessed: 17 June 2017).

Kaptelinin, V. (1996) 'Creating computer-based work environments: an empirical study of Macintosh users', in Proceedings of the 1996 ACM SIGCPR/SIGMIS conference on Computer personnel research, pp. 360-366.

Kreps, G. A. (1984) 'Sociological Inquiry and Disaster Research', Annual Review of Sociology, 10(1), pp. 309-330.

Liu, S. B. et al. (2008) 'In Search of the Bigger Picture: The Emergent Role of On-Line Photo Sharing in Times of Disaster', Proceedings of the 5th International ISCRAM Conference, 8(May), pp. 140-149. doi: -.

Ludwig, T. et al. (2015) 'CrowdMonitor: Mobile crowd sensing for assessing physical and digital activities of citizens during emergencies', in Proceedings of the 33rd Annual ACM Conference on Human Factors in Computing Systems, pp. 4083-4092. doi: 10.1145/2702123.2702265.

Ludwig, T., Siebigteroth, T. and Pipek, V. (2014) 'CrowdMonitor: Monitoring Physical and Digital Activities of Citizens During Emergencies', in Social Informatics, pp. 421-428.

Mark, G. J., Al-Ani, B. and Semaan, B. (2009) 'Resilience through technology adoption', in Proceedings of the 27th international conference on Human factors in computing systems - CHI 09. New York, New York, USA: ACM Press, p. 689. doi: $10.1145 / 1518701.1518808$.

Mark, G. and Semaan, B. (2008) 'Resilience in Collaboration: Technology as a Resource for New Patterns of Action', in Proceedings of the ACM 2008 conference on Computer supported cooperative work - CSCW' 08 . New York, New York, USA: ACM Press, p. 137. doi: 10.1145/1460563.1460585.

Nhan, J., Huey, L. and Broll, R. (2017) 'Digilantism: An analysis of crowdsourcing and the Boston marathon bombings', The British Journal of Criminology. Oxford University Press, 57(2), pp. 341-361. doi: 10.1093/bjc/azv118.

Orlikowski, W. J. (1995) 'Learning From Notes: Organizational Issues in Groupware Implementation', Readings in HumanComputer Interaction. Morgan Kaufmann, pp. 197-204. doi: 10.1016/B978-0-08-051574-8.50023-6.

Palen, L., Hiltz, S. R. and Liu, S. B. (2007) 'Citizen communications in crisis: anticipating a future of ICT-supported public participation', in CHI '07 Proceedings of the SIGCHI conference on Human factors in computing systems. San Jose, CA, USA: ACM New York, NY, USA, p. 10. Available at: http://dx.doi.org/10.1145/1240624.1240736. 
Peters, R. and de Albuquerque, J. P. (2015) 'Investigating images as indicators for relevant social media messages in disaster management', Proceedings of the ISCRAM 2015 Conference - Kristiansand, May 24-27, (2013).

Reuter, C. et al. (2015) 'XHELP: Design of a Cross-Platform Social-Media Application to Support Volunteer Moderators in Disasters', in Proceedings of the 33rd Annual ACM Conference on Human Factors in Computing Systems (CHI '15). ACM. New York, NY, USA, pp. 4093-4102. doi: 10.1145/2702123.2702171.

Reuter, C., Hughes, A. L. and Kaufhold, M.-A. (2018) 'Social Media in Crisis Management: An Evaluation and Analysis of Crisis Informatics Research', International Journal of Human-Computer Interaction. Taylor \& Francis, pp. 1-15. doi: $10.1080 / 10447318.2018 .1427832$.

Reuter, C. and Mentler, T. (2018) 'Human-computer interaction and social media in safety-critical systems-Editorial', Journal of Contingencies and Crisis Management, 26(1), pp. 2-3. doi: 10.1111/1468-5973.12192.

Shklovski, I., Palen, L. and Sutton, J. (2008) 'Finding community through information and communication technology in disaster response', in Proceedings of the ACM 2008 conference on Computer supported cooperative work - CSCW'08. New York, New York, USA: ACM Press, p. 127. doi: 10.1145/1460563.1460584.

Smith, M. A., Farnham, S. D. and Drucker, S. M. (2000) 'The Social Life of Small Graphical Chat Spaces', in Proceedings of the SIGCHI Conference on Human Factors in Computing Systems. New York, NY, USA: ACM (CHI '00), pp. $462-469$. doi: $10.1145 / 332040.332477$.

Starbird, K. (2011) 'Digital volunteerism during disaster: Crowdsourcing information processing', in Conference on human factors in computing systems, pp. 7-12.

Starbird, K. and Palen, L. (2010) Pass it on?: Retweeting in mass emergency. International Community on Information Systems for Crisis Response and Management.

Starbird, K. and Palen, L. (2011) ""Voluntweeters": Self-Organizing by Digital Volunteers in Times of Crisis', in Proceedings of the SIGCHI conference on human factors in computing systemsCHI 2011, May 7-12, 2011, Vancouver, BC, Canada., pp. 1071-1080.

Starbird, K. and Palen, L. (2013) 'Working and sustaining the virtual "Disaster Desk"', in Proceedings of the 2013 conference on Computer supported cooperative work - CSCW'13. New York, New York, USA: ACM Press, pp. 491-502. doi: 10.1145/2441776.2441832.

Tapia, A. H., LaLone, N. J. and Kim, H.-W. (2014) 'Run amok: Group crowd participation in identifying the bomb and bomber from the Boston marathon bombing', in ISCRAM, pp. 265-274. doi: 10.4018/IJISCRAM.2014100105.

Vieweg, S. et al. (2008) Collective Intelligence in Disaster: Examination of the Phenomenon in the Aftermath of the 2007 Virginia Tech Shooting. Boulder, CO: University of Colorado.

Vieweg, S. et al. (2010) 'Microblogging during two natural hazards events: what twitter may contribute to situational awareness', in Proceedings of the 28th international conference on human factors in computing systems. ACM, pp. 10791088. doi: 10.1145/1753326.1753486. 